Tjalling C. Koopmans Research Institute

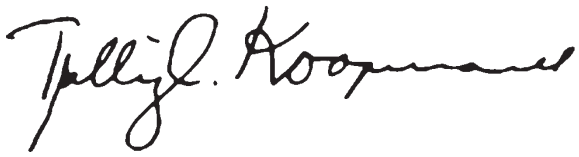

Discussion Paper Series nr: 04-27

\title{
When Will Judgment Proof Injurers Take Too Much Precaution?
}

Giuseppe Dari-Matticci

Gerrit de Geest 


\section{Tjalling C. Koopmans Research Institute Utrecht School of Economics Utrecht University}

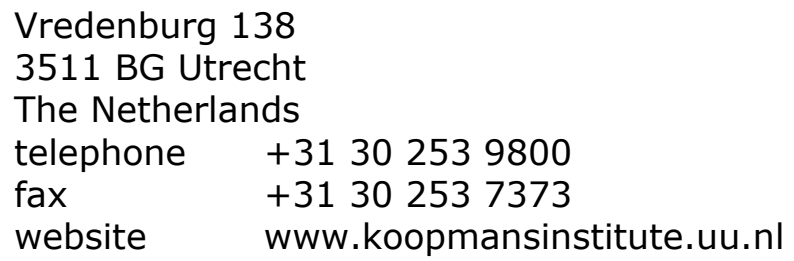

In the discussion papers series the Koopmans Institute publishes results of ongoing research for early dissemination of research results, and to enhance discussion with colleagues.

Please send any comments and suggestions on the Koopmans institute, or this series to M.Damhuis@econ.uu.nl

ontwerp voorblad: WR IK Utrecht

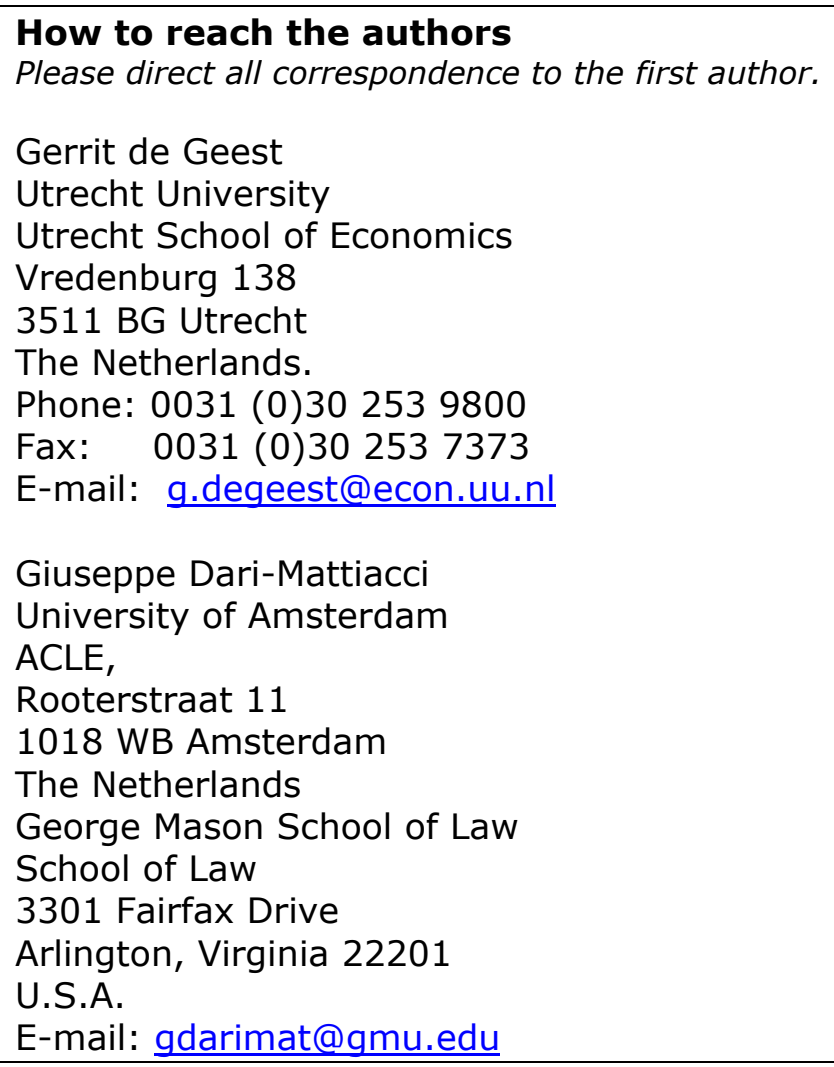




\title{
When Will Judgment Proof Injurers Take Too Much Precaution?*
}

\author{
Giuseppe Dari-Matticcia \\ Gerrit de Geest $^{b}$
}

\author{
aUniversiteit van Amsterdam \\ ACLE \\ George Mason University, \\ School of Law \\ bUtrecht School of Economics \\ Utrecht University
}

November 2004

\begin{abstract}
This article identifies the conditions under which potentially insolvent injurers overinvest in precaution. We show that this may happen only with respect to precautionary measures that reduce the probability of the accident. No such result occurs if precaution only reduces the magnitude of the harm. Contrary to the literature, we find that over-precaution may also occur when precaution is nonmonetary. The reason being is that over-precaution can not only be due to the implicit precaution-subsidy effect (the fact that care-taking reduces the injurer's exposure to liability when precaution is monetary) but also to a substitution effect between precaution that reduces the probability of accidents and precaution that reduces the magnitude of the harm. Finally, we find that when the injurer's wealth is sufficiently low, precautions may actually be lower when they are monetary than when they are non-monetary, despite the implicit precaution subsidy in the former case.
\end{abstract}

Keywords: insolvency, judgement, liability, bankruptcy, over precaution

JEL classification: $\mathrm{K} 13, \mathrm{~K} 32$

\section{Acknowledgements}

We would like to thank Thomas Eger, Eric Langlais, Nuno Garoupa, Vicente Mendes, Jef de Mot, Francesco Parisi, Daniel Rubinfeld, Ram Singh, Georg von Wangenheim, two anonymous referee and the participants in the seminar at Hamburg University for helpful comments on previous versions of this article. Devlin Cooper provided valuable editorial assistance. Giuseppe Dari-Mattiacci gratefully acknowledges the financial support provided by the European Commission, the Marie Curie Fellowship Programme in Law and Economics at Hamburg University. 


\section{Introduction: one-pocket v. two-pocket models}

An injurer is said to be judgment proof if his assets are insufficient to compensate for the harm he has caused or if his liability is limited by statute. Summers (1983) and Shavell (1986) showed that judgment proof injurers tend to take too little precaution; this is because not all accident losses are internalized. Consequently, correcting under-precaution is usually seen as one important goal of policy measures addressed to potentially insolvent injurers. ${ }^{1}$ Instead, this paper shows that the relationship between potential insolvency and precaution decisions is more complex than that. In particular, potentially insolvent injurers may take a higher level of precautions than is socially optimal or substitute some precautionary measures for others, depending on the available precaution technologies. ${ }^{2}$

In order to prove his results, Shavell (1986) used a standard probability model, ${ }^{3}$ in which precaution reduces the probability but not the magnitude of accidental harm. In addition, Shavell made the simplifying assumption that the injurer's precaution expenses do not reduce the assets available for compensation. We refer to this model as a two-pocket model because the injurer behaves as if he had two separate pockets: one limited, for liability payments, and another unlimited, for precaution. This scenario may arise in two cases: non-monetary precautionary measures (which do not reduce the injurer's assets) and statutory caps to the injurer's liability (which is not affected by precaution expenditures).

Beard (1990) relaxed this assumption and studied a one-pocket probability model, in which precaution and liability expenses are paid out of the same pocket and, thus, care-taking reduces the assets available for compensation. He showed that under certain conditions the injurer may take over-precaution. Beard's results have recently

\footnotetext{
${ }^{1}$ One traditional justification for regulatory standards is the failure of tort liability to provide adequate incentives to insolvent injurers. See, among others, Shavell (1984), Rose-Ackerman (1991), Schmitz (2000). Minimum asset and liability insurance requirements are also advocated with the same purpose. See for a recent contribution Shavell (2004).

${ }^{2}$ We analyze the precaution decisions of injurers given a certain threshold on their liability (limited assets or a statutory limit on the amount of damages). Nevertheless, the injurer's assets may be endogenously determined according to the legal rule in place and the characteristics of the accident. We ignore this problem in the present analysis. See on this issue Boyd and Ingberman (1999).

${ }^{3}$ Probability models are standard in the literature on liability (see Dari-Mattiacci and De Geest, forthcoming, for a review of the few exceptions) and also in the insurance literature, see for example Sweeney and Beard (1992) and Gollier, Koehl and Rochet (1997).
} 
been reconsidered by Miceli and Segerson (2003), who have expanded on the negligence rule and positive litigation costs under the same type of model.

Thus, so far the literature has focused on two models: the two-pocket probability model of Shavell and the one-pocket probability model by Beard. Building on our previous contribution, ${ }^{4}$ this paper re-examines this problem by considering six additional models constructed on three different precaution technologies in both a one-pocket and a two-pocket variant. We make a distinction between precaution that reduces the probability and precaution that reduces the magnitude of accidental harm. ${ }^{5}$ For example, precaution taken by a pilot only affects the probability of an air crash, while precaution taken by a motorist clearly affects both the probability of injuring a pedestrian and the severity of the injury.

We examine four different stereotypical cases: the probability model (precaution only reduces the probability of an accident), the magnitude model (precaution only reduces the magnitude of the harm), the joint-probability-magnitude model (precaution jointly affects both dimensions) and the separate-probability-magnitude model (the injurer takes two different precautionary measures affecting probability and magnitude, respectively).

We study the pattern of the injurer's precaution decision under the four models in both a one-pocket version and a two-pocket version. In total, we examine eight different accident models and show a general result: the over-precaution effect arises only for those precautionary measures that reduce the probability of accidents.

Next, we discuss the logic of this result and find two reasons why the injurer's potential insolvency may result in socially excessive precaution. Beard's explanation was that care-taking reduces the assets available for paying damages and hence it is as if a part of the cost of precaution taken by the injurer were externalized to the victim in the form of reduced compensation. We demonstrate that this implicit precaution subsidy is not powerful enough to induce excessive precaution also for magnitude

\footnotetext{
${ }^{4}$ See Dari-Mattiacci and De Geest, forthcoming, in which we analyze the effect of different precaution technologies in two-pocket models. In this study we extend the same type of analysis to one-pocket models and to a comparison between them.

${ }^{5}$ To our knowledge, the literature has never made a distinction between these different situations in connection with the over-precaution effect. Boyd and Ingberman (1994) analyzed the effect of different precaution technologies in some versions of a two-pocket model and thus did not touch upon the over-precaution effect. In the insurance literature the reduction of the magnitude of the loss is usually called 'self-insurance', while the reduction of its probability is called 'self-protection'. See Ehrlich and Becker (1972). This literature, however, does not focus on the behavior of judgment proof individuals as we do.
} 
reducing precaution.

As well as this now standard explanation, there is a second reason why potentially insolvent injurers may take socially excessive precaution. Under our separate-probability-magnitude model, it may be optimal for an injurer to substitute probability precautions for magnitude precautions. More precisely, the injurer may reduce his level of magnitude precautions to zero (a choice that renders him insolvent) and instead increase his level of probability precautions over the socially optimal level. This strategy is advantageous for the injurer because part of the cost of altering the balance between the two forms of precaution is externalized on the victim due to insolvency.

Surprisingly, injurers may be induced to make excessive precaution investments even when they would have been solvent if they had taken the socially optimal level of precaution. Contrary to the literature, we find that this result also obtains under a two-pocket model, that is, when care-taking does not reduce the injurer's assets, and is reinforced in a one-pocket model.

Finally, we show a counterintuitive result. We have already noted that in onepocket models the injurer benefits from an implicit precaution subsidy. Thus, it may seem reasonable to conclude that, ceteris paribus, the injurer's level of precautions will always be higher than in two-pocket models. However, when the injurer's wealth is low, precautions taken in one-pocket models may actually be lower than those taken in two-pocket models, despite the precaution subsidy. This is because, in onepocket models, the injurer's level of precaution is constrained by the injurer' wealth, while this limit is absent in two-pocket models.

The formal analysis is structured as follows. Section 2 presents the formal analysis of the injurer's precaution decisions. We begin by the study of probability models and compare the precaution decision of injurers under the two-pocket version and under the one-pocket version. Later we study magnitude models and show that the equilibrium level of precaution is identical in the two versions of the model. Further, we analyze the other two models: the joint-probability-magnitude model and the separate-probability-magnitude model. Section 3 discusses our results in an informal way and provides some clarifications on the basic logic behind them. Section 4 concludes with some implications of our results. 


\section{Formal analysis}

\subsection{Probability models}

Accidents occur under strict liability between a passive victim and an injurer, strangers to each other and risk-neutral. ${ }^{6}$ Injurers have limited assets, which we assume are exogenously determined. All functions are continuously differentiable to any desired order. Let:

$$
\begin{aligned}
& x=\text { the injurer's precaution cost, } x \geq 0 ; \\
& p(x)=\text { probability of an accident, } 0<p(x)<1, p^{\prime}<0, p^{\prime \prime}>0 ; \\
& h \quad=\text { magnitude of the harm, } h>0 ; \\
& t \quad=\text { the injurer's assets, } t>0 .
\end{aligned}
$$

We employ the standard social cost function:

$$
S(x)=p(x) h+x
$$

Let $x^{*}$ denote the (unique) level of precaution that minimizes Exp. (1) and let it be positive. The injurer chooses the level of precaution that minimizes the sum of expected liability and precaution cost. ${ }^{7}$

Proposition 1. In a two-pocket probability model:

(1.I) The injurer takes $x *$ if $t$ is equal to or greater than $h$;

(1.II) Otherwise, he takes $x_{2}<x^{*}$, which increases continuously in $t$.

In a one-pocket probability model:

(1.III) The injurer takes $x *$ if $t$ is equal to or greater than some threshold level, which is greater than $h+x *$;

(1.IV) Otherwise he takes $x_{1}$, which increases continuously in $t$;

(1.V) As $t$ increases, $x_{1}$ is initially less than, then equal to and finally greater than

\footnotetext{
${ }^{6}$ Since our aim is to analyze the precaution decisions of injurers and not their insurance decisions, we consider the simple case of risk neutrality. Considering risk aversion would not change the crux of our argument, which rests on the finding that the behavior of insolvent injurers depends on the available precaution technology and on whether or not precaution expenditures reduce the exposure to liability.

${ }^{7}$ The two-pocket version of this model is close to Shavell (1986). The one-pocket version simplifies the model of Beard (1990) to make the results easily comparable to Shavell's model. Since it is not essential for the result to hold, we do not use a probability distribution for the harm as Beard does, but rather assume that it is known ex ante by the injurer. In addition to what has been shown by Miceli and Segerson (2003), we compare the levels of precaution taken under the one-pocket model with the level of precaution taken under the two-pocket model. Our solution algorithm is different from the ones employed by Beard (1990) and Miceli and Segerson (2003).
} 
$x *$

(1.VI) As $t$ increases, $x_{1}$ is initially less, than equal to and finally greater than $x_{2}$.

Proof: We employ the following algorithm solution: a) Find the levels of $x$ that minimize the total expenditures for a solvent and an insolvent injurer - a marginal analysis; b) Compare the total expenditures and choose whether it is optimal to be solvent or insolvent - an inframarginal analysis; c) Verify that this is always a valid solution, that is, that the injurer is actually solvent (insolvent) at the chosen levels of precaution.

In a two-pocket probability model, the injurer's expenditure function is:

$$
\left\{\begin{array}{lll}
J(x)=p(x) h+x & \text { if } & h \leq t \\
J_{2}(x)=p(x) t+x & \text { if } & h>t
\end{array}\right.
$$

Let $x_{2}$ denote the level of $x$ that minimizes $J_{2}(x)$ and let it be positive; $x *$ minimizes $J(x)$. The solution algorithm trivially applies and claims (1.I) and (1.II) are selfevident.

In a one-pocket probability model, the insolvent injurer pays compensation equal to $t$ $x$. His expenditure function is:

$$
\left\{\begin{array}{lll}
J(x)=p(x) h+x & \text { if } & h+x \leq t \\
J_{1}(x)=p(x)[t-x]+x & \text { if } & h+x>t
\end{array}\right.
$$

Let $x_{1}$ denote the level of $x$ that minimizes $J_{l}(x)$, and let it be positive. The injurer takes $x^{*}$ if $J\left(x^{*}\right) \leq J_{1}\left(x_{1}\right)$. He takes $x_{1}$, otherwise. Thus, $x *$ is a solution iff:

$$
t \geq\left\{p\left(x^{*}\right) h+x *-\left[1-p\left(x_{1}\right)\right] x_{1}\right\} / p\left(x_{1}\right)
$$

Claim (1.III): by the Envelop Theorem, $d J_{1}\left(x_{1}\right) / d t>0$. Thus, since $J\left(x^{*}\right)$ is constant in $t$, there exists a unique threshold level of $t$ equal to the right-hand side of Exp. (4) such that the injurer always takes $x^{*}$ if his assets are larger than or equal to such a threshold; he takes $x_{1}$, otherwise. If $t=h+x^{*}$, then $J\left(x^{*}\right)=J_{1}\left(x^{*}\right)>J_{1}\left(x_{1}\right)$; thus, the threshold level of $t$ must be greater than $h+x^{*}$ for $J\left(x^{*}\right)<J_{1}\left(x_{1}\right)$. Claim (1.IV): by the Implicit Function Theorem on the f.o.c. for $J_{l}(x), d x_{l} / d t>0$. Claim (1.V): Assume 
$t=h+x^{*}$. Evaluating the first derivative of $J_{1}(x)$ at $x^{*}$ we obtain $p^{\prime}\left(x^{*}\right)\left[t-x^{*}\right]+1-$ $p\left(x^{*}\right)<0$, because the first two terms amount to zero by the f.o.c. for $J(x)$, and the third term is negative; thus, $x_{1}>x^{*}$. It can be shown that when $t$ approaches $0, x_{1}$ also approaches 0 ; thus, for initial levels of $t, x_{1}<x^{*}$. As $t$ increases, $x_{1}=x^{*}$ and then $x_{1}>x^{*}$. Claim (1.VI): Evaluate the first derivative of $J_{1}(x)$ at $x_{2}$ and note that $x_{1} \leq x_{2}$ if $p\left(x_{2}\right)+p^{\prime}\left(x_{2}\right) x_{2} \leq 0$, which can be interpreted as a condition depending on the elasticity of the probability function or - given $p^{\prime}\left(x_{2}\right)=-1 / t-$ it can be rewritten as $t \leq x_{2} / p\left(x_{2}\right)$; $x_{1}>x_{2}$, otherwise. At $t=h$ the criterion becomes $h \leq x * / p\left(x^{*}\right)$; therefore $x_{1}$ crosses $x_{2}$ to the left of $t=h$ (as in figure 1) if $x^{*}<p\left(x^{*}\right) h$ - the cost of precaution is less than the expected accident loss at the social optimum,$- x_{1} \operatorname{crosses} x_{2}$ at (or to the right of) $t=h$, if $x^{*} \geq p\left(x^{*}\right) h$.

Finally, to verify point c) above, if $x^{*}$ is chosen, the injurer must actually be solvent at $x^{*}\left(h+x^{*} \leq t\right)$, as implicitly required by Exp. (3). Assume the solution is $x^{*}$ and, contrary to our claim, $h+x^{*}>t$. Then we could write $p\left(x^{*}\right) h+x^{*}>p\left(x^{*}\right)\left[t-x^{*}\right]+x^{*}>$ $p\left(x_{t}\right)\left[t-x_{t}\right]+x_{t}$ (by definition of $\left.x_{t}\right)$. This would imply $J\left(x^{*}\right)>J_{t}\left(x_{t}\right)$ and, thus, the solution would be $x_{t}$, which contradicts the premise. Therefore, if $x^{*}$ is the solution, then $h+x * \leq t$ must be satisfied. Thus, the injurer chooses the socially optimal level of precaution only if he is actually solvent at that level A similar contradiction arises if $x_{t}$ is chosen and $h+x_{t}>t$ is not satisfied. Thus, the injurer chooses an inefficient level of precaution only if he is actually insolvent at that level. This guarantees that our algorithm provides valid results. A similar proof for point c) applies to the other models and will not be repeated. Q.E.D.

\subsection{Magnitude models}

Modifying the previous setting, let:

$$
\begin{aligned}
& p=\text { probability of an accident, } 0<p<1 ; \\
& h(x)=\text { magnitude of the harm, } h(x)>0, h^{\prime}<0, h^{\prime}>0 .
\end{aligned}
$$

The social cost function is:

$$
S(x)=p h(x)+x
$$

Let $x *$ denote again the socially optimal level of precaution. 
Proposition 2. In a two-pocket magnitude model:

(2.I) The injurer takes $x *$ if $t$ is equal to or greater than $h\left(x^{*}\right)+x * / p$;

(2.II) Otherwise, he takes $x_{2}=0$.

In a one-pocket magnitude model:

(2.III) The injurer takes the same levels of precaution as in the two-pocket version (either $x^{*}$ or $x_{1}=x_{2}=0$ ) for the same threshold level of $t$.

Proof: In a two-pocket magnitude model, the injurer's expenditure function is:

$$
\left\{\begin{array}{lll}
J(x)=p h(x)+x & \text { if } & h(x) \leq t \\
J_{2}(x)=p t+x & \text { if } & h(x)>t
\end{array}\right.
$$

$J_{2}(x)$ is minimized by $x_{2}=0$. The injurer takes $x^{*}$ if $J\left(x^{*}\right) \leq J_{t}(0)$. He takes $x_{2}=0$ otherwise. Thus, $x *$ is taken iff:

$$
t \geq h\left(x^{*}\right)+x^{*} / p
$$

There exist a unique threshold level of $t$ equal to the right-hand side of Exp. (7) such that the injurer always takes $x^{*}$ if his assets are larger than this level and $x=0$ otherwise.

In a one-pocket magnitude model, the injurer's expenditure function is:

$$
\left\{\begin{array}{lll}
J(x)=p h(x)+x & \text { if } & h(x)+x \leq t \\
J_{1}(x)=p[t-x]+x & \text { if } & h(x)+x>t
\end{array}\right.
$$

$J_{1}(x)$ is minimized by $x=0$. Since $J_{1}(0)=J_{2}(0)$, the injurer takes the same levels of precaution as in the previous model. Q.E.D.

\section{[Figure 1]}

\subsection{Joint-probability-magnitude models}

If the same precaution reduces the probability and the magnitude of the harm (jointprobability-magnitude model) at the same time, the social cost function is:

$$
S(x)=p(x) h(x)+x
$$

Let $x *$ denote again the socially optimal level of precaution. 
Proposition 3. In a two-pocket joint-probability-magnitude model:

(3.I) The injurer takes $x *$ if $t$ is equal to or greater than some threshold level, which is greater than $h\left(x^{*}\right)$;

(3.II) Otherwise, he takes $x_{2}<x^{*}$, which increases continuously in $t$.

In a one-pocket probability model:

(3.III) The injurer takes $x *$ if $t$ is equal to or greater than some threshold level, which is greater than $h\left(x^{*}\right)+x *$;

(3.IV) Otherwise he takes $x_{1}$, which increases continuously in $t$;

(3.V) As $t$ increases, if $-h^{\prime}\left(x^{*}\right)<1, x_{1}$ is initially less than, then equal to and finally greater than $x^{*}$; if $-h^{\prime}\left(x^{*}\right)=1, x_{1}$ approaches $x^{*}$; if $-h^{\prime}\left(x^{*}\right)>1, x_{1}<x^{*}$;

(3.VI) As $t$ increases, $x_{1}$ is initially less, than equal to and finally greater than $x_{2}$.

Proof: In a two-pocket joint-probability-magnitude model, the injurer's expenditure function is:

$$
\left\{\begin{array}{lll}
J(x)=p(x) h(x)+x & \text { if } & h(x) \leq t \\
J_{2}(x)=p(x) t+x & \text { if } & h(x)>t
\end{array}\right.
$$

Let $x_{2}$ denote the level of $x$ that minimizes $J_{2}(x)$, and let $x_{2}$ be positive. The injurer takes $x^{*}$ if $J\left(x^{*}\right) \leq J_{2}\left(x_{2}\right)$. He takes $x_{2}$, otherwise. Thus, $x^{*}$ is a solution iff:

$$
t \geq\left[p\left(x^{*}\right) h\left(x^{*}\right)+x^{*}-x_{2}\right] / p\left(x_{2}\right)
$$

Claim (3.I): by the Envelop Theorem, $d J_{2}\left(x_{2}\right) / d t>0$. Thus, since $J\left(x^{*}\right)$ is constant in $t$, there exists a unique threshold level of $t$ equal to the right-hand side of Exp. (11) such that the injurer always takes $x^{*}$ if his assets are larger than or equal to such a threshold; he takes $x_{2}$, otherwise. If $t=h\left(x^{*}\right)$, then $J\left(x^{*}\right)=J_{2}\left(x^{*}\right)>J_{2}\left(x_{2}\right)$; thus, the threshold level of $t$ must be greater than $h\left(x^{*}\right)$ for $J\left(x^{*}\right)<J_{2}\left(x_{2}\right)$. Claim (3.II): In DariMattiacci and De Geest (forthcoming) we prove that $x_{2}<x *$. By the Implicit Function Theorem on the f.o.c. for $J_{2}(x), d x_{2} / d t>0$.

In a one-pocket joint-probability-magnitude model, the injurer's expenditure function is: 


$$
\left\{\begin{array}{lll}
J(x)=p(x) h(x)+x & \text { if } & h(x)+x \leq t \\
J_{1}(x)=p(x)[t-x]+x & \text { if } & h(x)+x>t
\end{array}\right.
$$

Let $x_{1}$ denote the level of $x$ that minimizes $J_{l}(x)$, and let $x_{1}$ be positive. The injurer takes $x *$ if $J(x *) \leq J_{1}\left(x_{1}\right)$. He takes $x_{1}$, otherwise. Thus, $x *$ is a solution iff:

$$
t \geq\left\{p\left(x^{*}\right) h\left(x^{*}\right)+x^{*}-\left[1-p\left(x_{1}\right)\right] x_{1}\right\} / p\left(x_{1}\right)
$$

Claims (3.III) and (3.IV) may be easily proven as claims (3.I) and (3.II) above. Claim (3.V): By the Implicit Function Theorem on the f.o.c. for $J_{l}(x), d x_{1} / d t>0$. The greatest possible level of $x_{1}$ that is a solution must satisfy two conditions, $J_{l}\left(x_{1}\right)=J\left(x^{*}\right)$ - that is, condition (14) is binding - and $J_{l}{ }^{\prime}\left(x_{l}\right)=0=J^{\prime}\left(x^{*}\right)$. For such largest level to be $x_{l} \geq x^{*}$ we must have $J_{l}\left(x^{*}\right) \leq J\left(x^{*}\right)$, which implies $t \leq h\left(x^{*}\right)+x^{*}$. Substituting into $J_{l}{ }^{\prime}\left(x^{*}\right) \leq 0=J^{\prime}\left(x^{*}\right)$, we obtain $-h^{\prime}\left(x^{*}\right) \leq 1$. It is easy to see that for the largest level of $x_{1}$ to be less than $x^{*}$, we must have $-h^{\prime}\left(x^{*}\right)>1$. The proof for claim (3.VI) is the same as for claim (1.VI). Q.E.D.

\subsection{Separate-probability-magnitude models}

If two independent precautionary measures, $s$ and $z$, reduce the probability and the magnitude of the harm, respectively (separate-probability-magnitude model), the social cost function is: ${ }^{8}$

$$
S(s, z)=p(s) h(z)+s+z
$$

Let $s^{*}$ and $z^{*}$ be the (unique) levels of $\mathrm{s}$ and $\mathrm{z}$ that minimize Exp. (15) and let them be positive.

Proposition 4. In a two-pocket separate-probability-magnitude model:

(4.I) The injurer takes $s^{*}$ and $z^{*}$ if $t$ is equal to or greater than some threshold level, which is greater than $h\left(z^{*}\right)$;

(4.II) Otherwise, he takes $z_{2}=0$ and $s_{2}$;

(4.III) As $t$ increases, $s_{2}$ is initially less than, then equal to and finally greater than $s^{*}$.

In a one-pocket separate-probability-magnitude model:

\footnotetext{
${ }^{8}$ Exp. (10) is assumed to be a strictly convex function of $s$ and $z ; p$ and $h$ are assumed to have the same
} 
(4.IV) The injurer takes $s^{*}$ and $z^{*}$ if $t$ is equal to or greater than some threshold level, which is greater than $h\left(z^{*}\right)+\mathrm{s}^{*}+\mathrm{z}^{*}$;

(4.V) The threshold level of $t$ in the one-pocket model - see (4.IV) - is greater than the same threshold in the two-pocket model - see(4.I);

(4.VI) Otherwise, he takes $z_{l}=0$ and $s_{1}$;

(4.VII)As $t$ increases, $s_{1}$ is initially less than, then equal to and finally greater than $s^{*}$;

(4.VIII) As $t$ increases, $s_{1}$ is initially less than, then equal to and finally greater than $s_{2}$.

Proof: In a two-pocket separate-probability-magnitude model, the injurer's expenditure function is:

$$
\left\{\begin{array}{lll}
J(s, z)=p(s) h(z)+s+z & \text { if } & h(z) \leq t \\
J_{2}(s, z)=p(s) t+s+z & \text { if } & h(z)>t
\end{array}\right.
$$

Let $s_{2}$ and $z_{2}$ denote the levels of $s$ and $z$ that minimize $J_{2}(s, z)$, and let $s_{2}$ be positive. Clearly $z_{2}=0$. The injurer takes $s^{*}$ and $z^{*}$ if $J\left(s^{*}, z^{*}\right) \leq J_{2}\left(s_{2}, \mathrm{z}_{2}\right)$. He takes $s_{2}$ and $z_{2}=0$, otherwise. Thus, $\left(s^{*}, z^{*}\right)$ is a solution iff:

$$
t \geq\left[p\left(s^{*}\right) h\left(z^{*}\right)+s^{*}+z^{*}-s_{2}\right] / p\left(s_{2}\right)
$$

Claim (4.I): by the Envelop Theorem, $d J_{2}\left(s_{2}\right) / d t>0$. Thus, since $J\left(s^{*}, z^{*}\right)$ is constant in $t$, there exists a unique threshold level of $t$ equal to the right-hand side of Exp. (17) such that the injurer always takes $\left(s^{*}, z^{*}\right)$ if his assets are greater than or equal to this threshold and $\left(s_{2}, z_{2}=0\right)$, otherwise. If $t=h\left(z^{*}\right)$, then $J\left(s^{*}, z^{*}\right)=J_{2}\left(s^{*}, z^{*}\right)>J_{2}\left(s_{2}, z_{2}\right)$; thus, the threshold level of $t$ must be greater than $h\left(z^{*}\right)$ for the injurer to take $\left(s^{*}, z^{*}\right)$, that is, for $J\left(x^{*}\right)<J_{2}\left(s_{2}, z_{2}\right)$. Claim (4.II) is self-evident. Claim (4.III): it is easy to show that when $t<h\left(z^{*}\right)$, then $s_{2}<s^{*}$; when $t=h\left(z^{*}\right)$, then $s_{2}=s^{*}$; when $t>h\left(z^{*}\right)$, then $s_{2}>s^{*}$.

In a one-pocket separate-probability-magnitude model, the injurer's expenditure function is: 


$$
\left\{\begin{array}{lll}
J(s, z)=p(s) h(z)+s+z & \text { if } & h(z)+s+z \leq t \\
J_{1}(s, z)=p(s)[t-s-z]+s+z & \text { if } & h(z)+s+z>t
\end{array}\right.
$$

Let $s_{l}$ and $z_{l}$ denote the levels of $s$ and $z$ that minimize $J_{l}(s, z)$, and let $s_{l}$ be positive. Clearly $J_{1}$ is linear in $z$ and, thus, $z_{1}=0$. The injurer takes $s^{*}$ and $z^{*}$ if $J\left(s^{*}, z^{*}\right) \leq J_{1}\left(s_{1}, \mathrm{z}_{1}\right)$. He takes $s_{1}$ and $z_{l}=0$, otherwise. Thus, $\left(s^{*}, z^{*}\right)$ is a solution iff:

$$
t \geq\left\{p\left(s^{*}\right) h\left(z^{*}\right)+s^{*}+z^{*}-\left[1-p\left(s_{1}\right)\right] s_{1}\right\} / p\left(s_{1}\right)
$$

Claim (4.IV): the proof is the same as for claim (4.I), considering $t=h\left(z^{*}\right)+\mathrm{s}^{*}+\mathrm{z}^{*}$ instead of $t=h\left(z^{*}\right)$. Claim (4.V) is self-evident; Claim (4.VI) has already been proven while proving claim (4.IV). Claim (4.VII): the proof is analogous to the proof of claim (4.III). Claim (4.VIII): the proof is analogous to the proof of claim (1.VI). Q.E.D.

Corollary 4.1. In a one-pocket separate-probability-magnitude model, an insolvent injurer might spend in total for $s+z$ more than a solvent injurer $\left(s_{t}>s^{*}+z^{*}\right)$.

Proof: Consider $t=h\left(z^{*}\right)+s^{*}+z^{*}$, and proceed as for the proof of claim (1.V). Q.E.D.

\section{Informal discussion and logic of our results}

The analysis of the previous section allows us to study how the amount of the injurer's assets affects his level of precaution in the different models. As we will see, the outcome depends on both the injurer's precaution technology - that is, on whether precaution reduces the probability of the accident or the magnitude of the resulting harm (or both) - and on whether or not precaution expenditures and damage compensation are paid out of the same budget.

\subsection{Over-precaution due to the precaution-subsidy effect}

We begin with an analysis of situations in which the injurer can only reduce the probability than an accidental harm occurs but cannot affect its magnitude (a probability model). If an airplane crashes, a cableway falls, a dam breaks down, or a building collapses, for example, the harm is likely to be independent of care-taking, 
which may nevertheless diminish the frequency of these events.

In two-pocket situations, the expenditure in precaution does not reduce the amount of money available to pay damages to the victim (as, for instance, when precaution is a non-monetary variable or when the limit on the injurer's liability is set by statute). As proposition 1 shows, the injurer will take socially optimal precaution only when his assets are at least as large as the harm to the victim. When the injurer's assets are less than that level, the injurer takes under-precaution, and the less the assets, the lower the precaution level, as a greater portion of the harm is externalized on the victim.

In one-pocket situations (for instance, when precaution is a monetary variable), the more the injurer invests in precaution, the less money will be available for compensation. Therefore, a fraction of the cost of precaution is recouped if an accident occurs in terms of more limited exposure to liability. This amounts to a precaution subsidy financed by the victim and tends to raise the level of precaution taken by the injurer.

However, a countervailing effect also occurs. Since precaution is paid out of the injurer's assets, when the assets are particularly limited, also the investment in precaution is somewhat constrained. This is clearly not so in the two-pocket model.

As a result, the relationship between the level of the injurer's assets and his level of precaution in the one-pocket model is very different from the two-pocket model, as depicted by figure 1 . When the assets are very limited, the injurer takes less than the optimal level of precaution in both cases, but the level of precaution is higher in the two-pocket model. For higher levels of the assets care-taking improves, the precaution subsidy starts prevailing, and hence the level of precaution taken in the one-pocket model rises above the two-pocket level.

When the assets approach the size of the harm, the level of precaution taken in two-pocket models rises up to the socially optimal level, while under the one-pocket model it continues to rise above that level due to the precaution subsidy. For even larger assets, however, the cost of taking such inefficiently high precaution levels rises above the cost of taking the socially optimal level of precaution, and care-taking drops to the optimal level, describing a non-monotonic pattern.

The situation is quite different in the mirror-case of magnitude models, in which 
the injurer's precaution reduces the magnitude but not the probability of the harm, as in nuisance cases and for most safety devises like bumpers, safety belts, and life boats. These situations are peculiar because the injurer takes either no precaution (when the assets are small enough) or optimal precaution. This is due to the fact that, when the injurer is insolvent, his precaution has no marginal effect on his expected liability, because he can neither reduce the probability (since we are in a magnitude model) nor the magnitude of the damages (since, being insolvent, he pays damages equal to all his assets).

Therefore, an insolvent injurer has no incentives to take any precaution and will choose a level equal to zero. It is easy to see that the level of precaution taken by insolvent injurers is the same under the one-pocket and the two-pocket model, as in both cases insolvent injurers take no precaution at all.

The injurer's choice is thus of inframarginal nature, as he decides between two discrete situations. Either the injurer is insolvent, takes no precaution, and bears a cost equal to his assets times the probability of an accident (which is exogenous in magnitude models) or he is solvent and takes the socially efficient level of precaution (which is the obvious choice when he bears the full harm).

The injurer's decision between these two alternatives depends on the levels of his assets. If they are very low, it will be convenient to opt for the former strategy, but when they reach a certain level, also the injurer's exposure to liability increases and it is advantageous to take socially optimal precaution. As figure 1 shows, the injurer precaution decision are represented by a discontinuous and, in a sense, binary pattern.

None of the results we have derived for the probability model applies to the magnitude model. To grasp the logic of this difference in outcomes, it is opportune to re-examine the injurer's precaution decisions in one-pocket models from a different angle.

The inefficiency of the injurer's choice is the result of a balance between two opposite forces. One is the precaution subsidy (precaution expenditures are externalized on the victim through a reduction in the injurer's exposure to liability), the other is the harm subsidy (accident losses are also externalized on the victim due to limited liability).

In one-pocket probability models, both these two subsidies are imperfect. In fact, 
only a portion of the marginal precaution costs is recoupable, as it is borne by the injurer when an accident does not occur. Likewise, only a portion of the marginal accident loss is externalized, because less precaution increases both the expected share of damages externalized on the victim and the expected portion paid by the injurer, since precaution reduces the probability of accidents. These effects are clear upon inspection of the insolvent injurer's marginal costs, a rearranged form of the first derivative of the second Exp. in (3).

$$
J_{1}^{\prime}(x)=p^{\prime}(x) h+1-p^{\prime}(x)(h-t)-\left[p^{\prime}(x) x+p(x)\right]
$$

The first two terms depict the social marginal costs (marginal harm plus marginal cost of precaution). The third term depicts the marginal harm subsidy, that is, the marginal portion of the harm externalized on the victim, which is lower than the marginal harm. The forth term depicts the marginal precaution subsidy, which is also lower than the marginal cost of precaution. As we have seen, either of these two effects may prevail.

A completely different scenario obtains in magnitude models, because, contrary to probability models, when the injurer is insolvent, any further reduction in precaution causes an increase in the harm but no increase in liability. From the first derivative of the second Exp. in (8), the insolvent injurer's marginal costs may be written as:

$$
J_{1}^{\prime}(x)=p h^{\prime}(x)+1-p h^{\prime}(x)-p
$$

From this formulation, it is evident that the injurer externalizes on the victim the entire marginal harm, while it only externalizes a portion $p$ of the marginal cost of precaution, equal to the probability that an accident occurs.

To illustrate with an example, in a magnitude model, if the injurer's assets are equal to 100 and the probability of an accident is equal to $10 \%$, a reduction in precaution that increases the harm from 120 to 240 has no effects on the injurer's expected liability. The latter remains equal to 10 , while the expected accident loss rises from 12 to 24 .

In contrast, in probability models, an insolvent injurer only partially externalizes the effects of reduced precaution, which increases the probability to pay a (truncated) damage award. For example, if the injurer's assets are equal to 100 and the harm is 
equal to 120 , a reduction in precaution that increase the probability from $10 \%$ to $20 \%$ rises both the expected accident loss (from 12 to 24) and, to a lesser extent, the expected injurer's liability (from 10 to 20). The expected accident loss increases by 12 in both cases.

However, while in the magnitude model such an increase is completely externalized, it is only partially externalized in the probability model (namely by 2 ). In other words, the harm-subsidy works at a 1:1 ratio in magnitude models, while at a lower one in probability models (1:6 in the example). The precaution-subsidy functions at a ratio lower than 1:1 in both models, as the cost of precaution is externalized on the victim in terms of reduced compensation only if an accident occurs, thus, with a probability lower than 1 . Therefore, the harm-subsidy always prevails on the precaution-subsidy in magnitude models and over-precaution never occurs.

In the formal analysis we have also accounted for situations in which the same precautionary measure reduces both the probability and the magnitude of accidental harm (the joint-probability-magnitude model). This is probably the most realistic model for most real life activities like driving a car, in which the speed affects both the probability and the harmfulness of accidents. We have shown that the results are similar to the probability model with some features of the magnitude model, namely, a discontinuity in the patterns of the injurer's precaution.

In particular, as figure 2 shows, over-precaution occurs only if $-h^{\prime}\left(x^{*}\right)<1$, that is, if the marginal reduction in the magnitude of the harm for a solvent injurer is lower than the marginal reduction in exposure to liability for an insolvent one (given the same probability of accident). This result highlights an important point. An injurer will increase his level of precaution over the socially optimal level of precaution, thus becoming insolvent, only if the expenditure in precaution reduces his liability more than it reduces the harm to the victim.

In turn, this obviously means that a joint-probability-magnitude model comes closer to a probability model when the effect of precaution on the expected harm is small, thus being prone to the over-precaution problem. On the contrary, when the effect of precaution on the harm is large, the model behaves in a way that is closer to magnitude models, thus being free from the over-precaution effect. 
When two different precautionary measures can be taken with the purpose of reducing probability and magnitude of the accidental harm (separate-probabilitymagnitude model), the probability precaution follows the patterns described in the probability model, while the magnitude precaution is subject to the same laws underlined above for the magnitude model. Therefore, as in figure 3, over-precaution may only result with respect to the probability precaution. Examples may be provided from activities like flying or traveling at see, in which radars reduce the probability of accidents, while parachutes and lifeboats reduce the magnitude of the harm.

\subsection{Over-precaution due to the substitution effect}

Over-precaution due to the substitution effect only occurs under the separateprobability-magnitude model, in which the injurer can control the probability of the accident and the magnitude of the harm through two different precautionary measures. In this case, even in a two-pocket model - that is, in the absence of a precaution subsidy - it may be optimal for an otherwise solvent injurer to lower his investment in magnitude precaution to zero and to increase his investment in probability precaution.

This choice may be advantageous because magnitude-probability costs are saved at the expense of victims. In fact, the increased harm is externalized to the extent that it exceeds the injurer's assets. In contrast, the benefit of increasing probability precaution is partially internalized by the injurer, as it reduces the probability of paying all his assets.

The latter advantage improves when the injurer's assets at risk of liability are sufficiently large, so that over-investing in probability precaution becomes more convenient. This result may also obtain in very counterintuitive circumstances, as injurers that would actually be solvent if they took the optimal levels of both precautionary measures may opt for this strategy.

Obviously, this effect is greater in one-pocket models, in which it is combined with the precaution subsidy. As corollary 4.1 and figure 3 show in a one-pocket model, substituting probability precaution for magnitude precaution, the injurer may spend in probability precaution more than the sum of the optimal expenditures in probability and magnitude precaution. 


\section{Conclusions and policy implications}

Our analysis has shown two main results that run contrary to the conventional wisdom. First, precaution that only reduces the magnitude of the harm is immune from the over-precaution effect. Second, over-precaution may result not only as a consequence of the subsidy effect generated by potential insolvency when care-taking reduces the injurer's assets, but also by a substitution effect between reducing the probability of the accident and reducing the magnitude of the harm, which may occur irrespective of whether or not precaution reduces the injurer's assets.

In general, the analysis suggests that over-precaution might arise irrespective of whether the accident is particularly unlikely and the expenditure on precaution is negligible in relation to the harm, and even when the injurer would have been solvent had he taken optimal precaution.

On a policy level, many potentially harmful activities are subject to regulation. One of the major justifications for regulatory intervention is the concern that tort law alone would fail to induce optimal precaution because of judgment-proof problems. ${ }^{9}$ Our analysis shows that it is important to distinguish between different categories of accidents.

Depending on the precaution technology available to the injurer and on whether or not precaution costs and damages are paid out of the same pocket, the efficiency goal may indeed be very different than predicted under the traditional approach.

Our analysis shows that under different conditions, different policies are needed. In some cases, in fact, the problem is not one of inducing the injurer to take more precaution, but rather to take less precaution (when the precaution-subsidy effect prevails) or to take the right balance of magnitude and probability precaution (when the substitution effect prevails). Policies that blindly focus on under-precaution problems may reach no result or even make the matter worse.

A traditionally supported solution is the implementation of a negligence rule. ${ }^{10}$ The negligence rule reduces the cost of taking the socially optimal level of care, as non-negligent injurers do not pay damages. It is easy to see that this solution is also

\footnotetext{
${ }^{9}$ See footnote 1 .

${ }^{10}$ The negligence rule is supported by Summers (1983), Shavell (1986), and Dari-Mattiacci and De Geest, forthcoming. Ganuza and Gomez (2004) provide an analysis of the socially optimal level of the negligence standard for judgment proof injurers, showing that it may be lower than for solvent injurers.
} 
valid when over-precaution enters the picture, because it clearly reduces the incentives to take more than the required level of care.

\section{References}

Beard, T. R. (1990), 'Bankruptcy and Care Choice,' Rand Journal of Economics, 21, 626-34.

Boyd, J., and D. E. Ingberman (1994), 'Noncompensatory Damages and Potential Insolvency,' Journal of Legal Studies, 23, 895-910.

Boyd, J., and D. E. Ingberman (1999), 'Do Punitive Damages Promote Deterrence?,' International Review of Law and Economics, 19, 47 - 68.

Dari-Mattiacci, G., and G. De Geest, forthcoming, 'Judgment Proofness under Four Different Precaution Technologies,' Journal of Institutional and Theoretical Economics.

Ehrlich, I., and G. S. Becker (1972), 'Market Insurance, Self-Insurance and SelfProtection,' Journal of Political Economy, 80, 623-648.

Ganuza, J. J., and F. Gomez (2004), 'Optimal Liability Rule under Limited Liability', UPF Working Paper No. 759.

Gollier, C., P. F. Koehl, and J. C. Rochet (1997), 'Risk-Taking Behavior with Limited Liability and Risk Aversion,' Journal of Risk and Insurance, 64, 347-370.

Miceli, T. J., and K. Segerson (2003), 'A Note on Optimal Care by Wealth Constrained Injurers,' International Review of Law and Economics, 23, 273-284.

Rose-Ackerman, S. (1991), 'Regulation and the Law of Torts,' American Economic Review, 81, 54-58.

Schmitz, P. W. (2000), 'On the Joint Use of Liability and Safety Regulation,' International Review of Law and Economics, 20, 371-382.

Shavell, S. (1984), 'Liability for Harm Versus Regulation for Safety,' Journal of Legal Studies, 13, 357-374.

Shavell, S. (1986), 'The Judgment Proof Problem,' International Review of Law and Economics, 6, 45-58. 
Shavell, S. (2004), 'Minimum Asset Requirements and Liability Insurance as Solutions to the Judgment-Proof Problem,' Harvard University, Olin Center for Law, Economics and Business, Discussion Paper n. 456.

Summers, J. (1983), 'The Case of the Disappearing Defendant: An Economic Analysis,' University of Pennsylvania Law Review, 132, 145-85.

Sweeney, G. H., and T. R. Beard (1992), 'The Comparative Statics of SelfProtection,' Journal of Risk and Insurance, 59, 301-309. 


\section{FIGURES}

FIGURE 1: Levels of precaution in the probability model and in the magnitude model

ProbabILITY Model

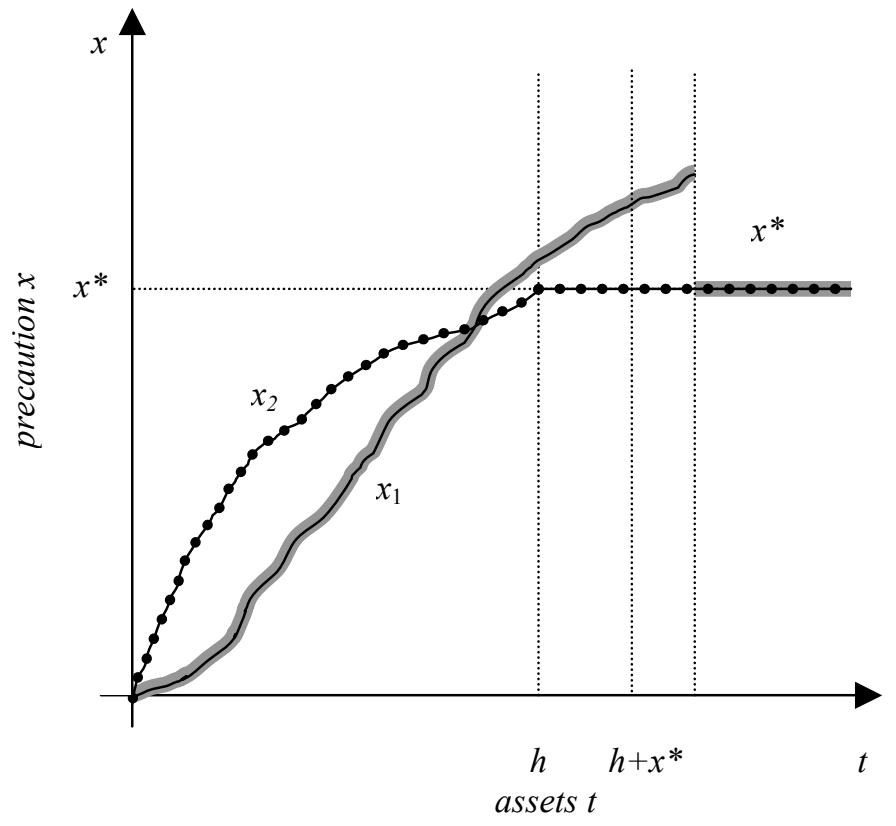

MAgnitude Model

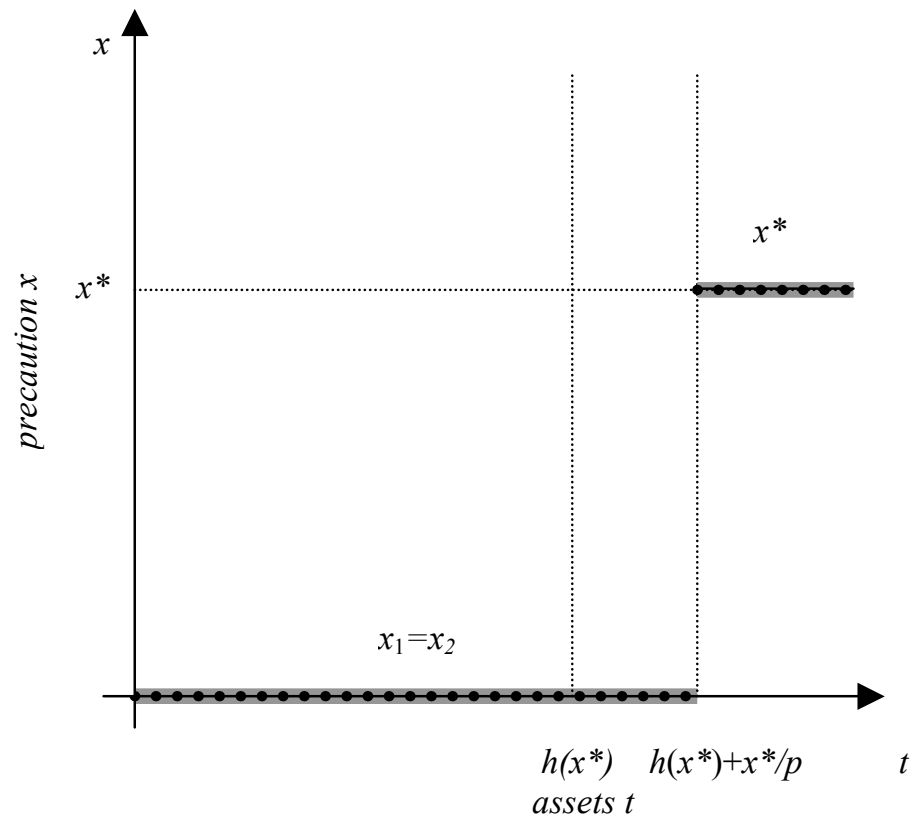


FIGURE 2: Levels of precaution in the joint-probability-magnitude model

One-pocket model

JoINT-PROBABILITY-MAGNITUdE MODEL WITH OVER-PRECAUTION, $-h^{\prime}\left(x^{*}\right)<1$

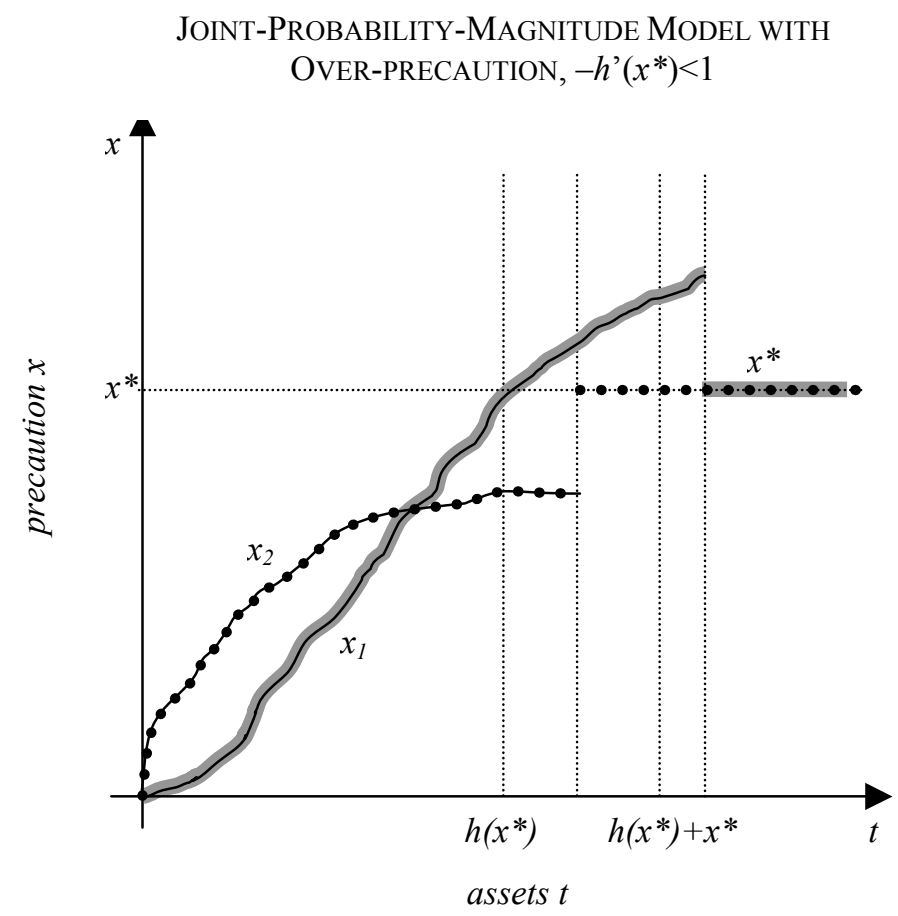

-.....・

Two-pocket model

JoINT-PRoBABILITY-MAGNITUdE ModeL WITHOUT OVER-PRECAUTION, $-h{ }^{\prime}(x *)>1$

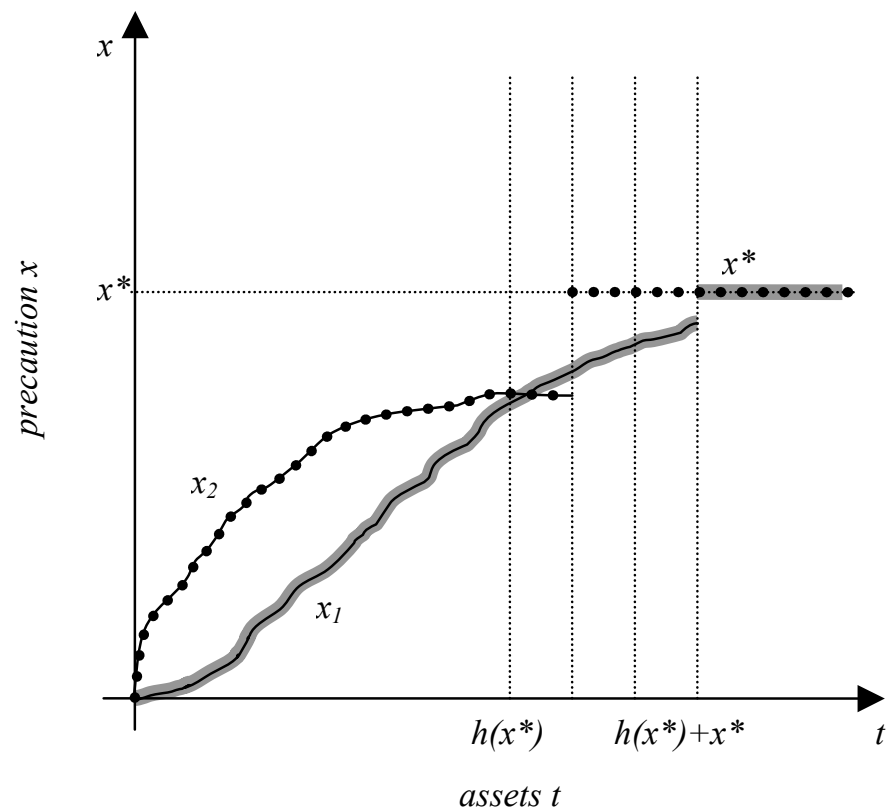


FIGURE 3: Levels of precaution in the separate-probability-magnitude model ( $z$ is drawn below $s^{*}$ only for convenience, the opposite may as well obtain)

\section{Probability precaution}

TWO-POCKET

SEPARATE-ProbABILITY-MAGNitude Model

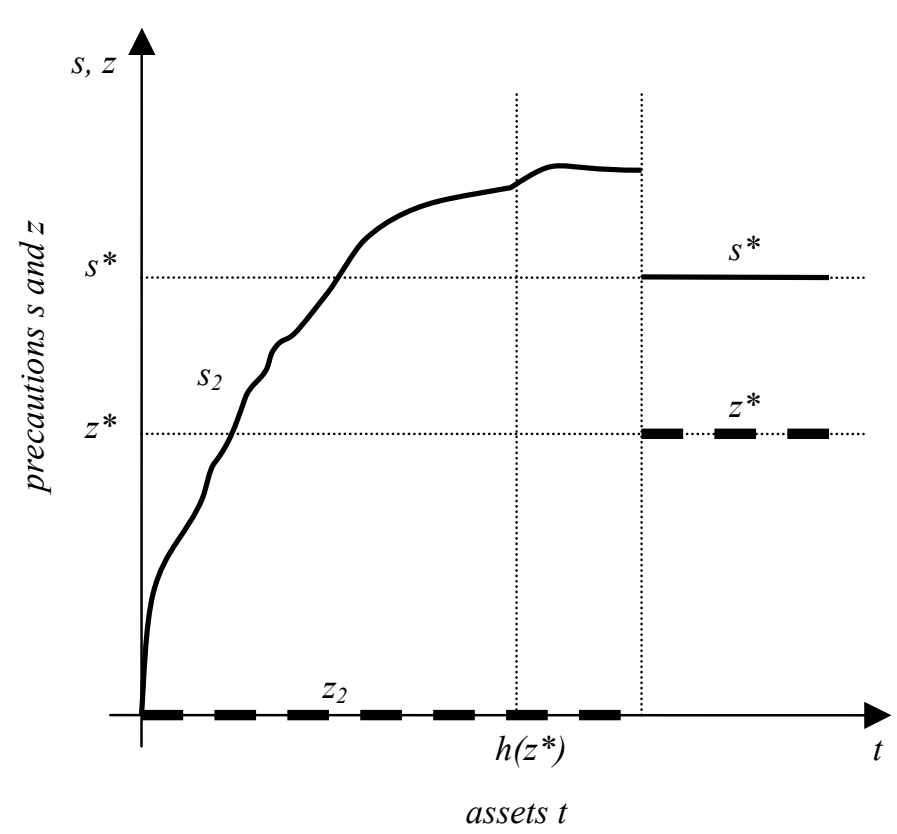

Magnitude precaution

ONE-POCKET

SEPARATE-PRoBABILITY-MAGNITUDE MODEL

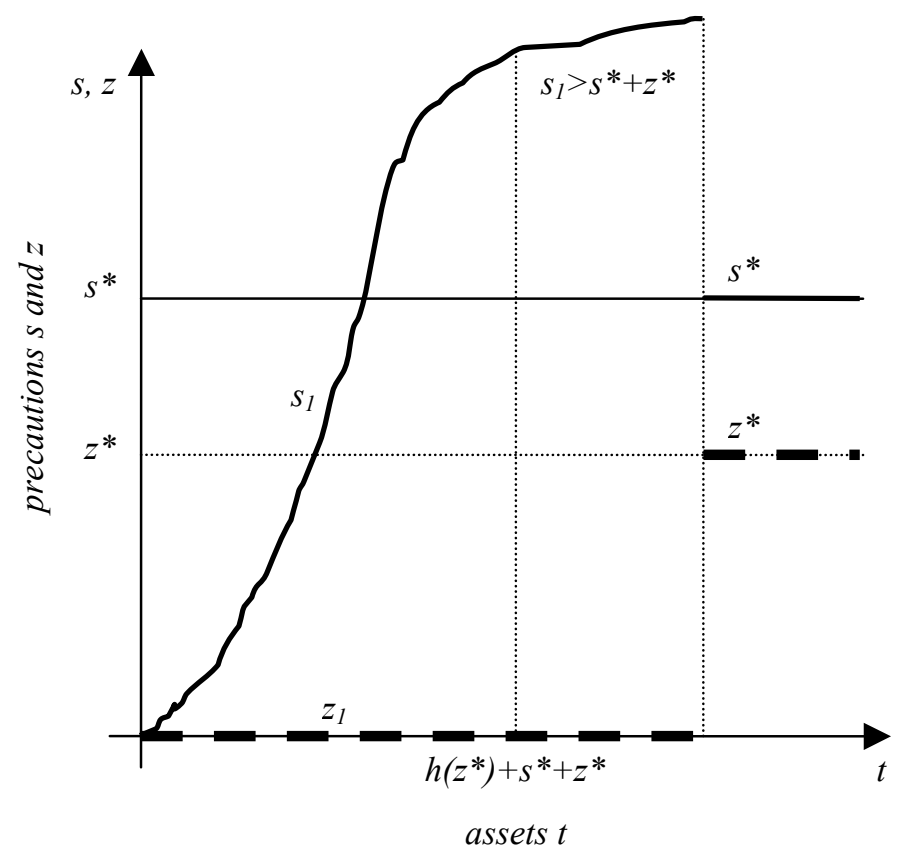

